\title{
$\nabla$ \\ IJCRR \\ Section: Healthcare \\ The Clinical Picture of Acute Obstructive Bronchitis in Children and the Rationale for Immunomodulatory Therapy
}

Sci. Journal Impact

Factor: 6.1 (2018)

ICV: 90.90 (2018)

(c) (i) (8)

Copyright@IJCRR

\author{
Ibatova Sh. M. ${ }^{1}$, Mamatkulova F. Kh' ${ }^{2}$ Ruzikulov N.Y. ${ }^{3}$ \\ 'Samarkand State Medical Institute, Samarkand, Uzbekistan; ${ }^{2}$ Samarkand State Medical lnstitute, Samarkand, Uzbekistan; \\ ${ }^{3}$ Samarkand State Medical Institute, Samarkand, Uzbekistan.
}

\section{ABSTRACT}

Introduction: Acute obstructive bronchitis is a widespread disease among children, leading to frequent relapses and complications. This pathology occupies one of the leading places in the structure of childhood morbidity and mortality. Analysis of risk factors in predicting the likelihood of acute obstructive bronchitis in children is essential for modern pulmonology. Acute pneumonia in patients with acute obstructive bronchitis occurs 4 times more often and almost always has a complicated course. When exposed to an infectious factor and other agents, various immunological changes are observed in children and the body's ability to develop a full-fledged post-infectious immunity is sharply reduced.

Result: We examined 65 children with acute obstructive bronchitis and 35 children with acute simple bronchitis without obstruction at the age of 3 months. up to 3 years. Children with acute obstructive bronchitis were at the age of 6 months. up to 3 years old, of which $39(60 \%)$ were boys, $26(40 \%)$ were girls. Immunological research was carried out in the clinical laboratory of the clinic of the Samarkand Medical Institute. The number of T-lymphocytes, T-helpers, T-suppressors, as well as B-lymphocytes, was determined by a modified method. The concentration of serum immunoglobulins A, M, G in peripheral blood was determined by the method of Mancini et al. Phagocytic activity of neutrophils was studied using latex particles.

The first group of patients was on traditional treatment with the inclusion of T-activin, and the second group of children was only on traditional treatment.

Conclusion: Dynamic immunological study revealed a decrease in factors of phagocytic activity of neutrophils, cellular immunity and developing transient insufficiency of humoral immunity with an increase in the duration of the disease.

Key Words: Acute obstructive bronchitis, Thymus gland, lymphocytes, T-activin, Children, Clinical and diagnostic observation.

\section{INTRODUCTION}

Among respiratory diseases, acute obstructive bronchitis (AOB) is widespread, leading to frequent relapses and severe complications. Obstructive forms of bronchitis occupy one of the leading places in the structure of childhood morbidity and mortality. ${ }^{1-5}$ The analysis of risk factors in predicting the likelihood of $\mathrm{AOB}$ in children is essential for modern pulmonology. Among patients with $\mathrm{AOB}$, acute pneumonia occurs 4 times more often and almost always has a complicated course. When exposed to an infectious factor and other agents in children, various immunological changes are observed, and the ability to develop full-fledged post-infectious immunity is also sharply reduced. ${ }^{3-6,7-10}$ With AOB, the indicator of the T-link of the immune status changes, which contributes to frequent intercurrent diseases and allergic manifestations. ${ }^{8,9}$ It is known that a decrease in cellular immunity is mediated through a violation of the production of biologically active hormone-like substances produced by the thymus. Therefore, a promising area of research is the search and implementation of methods that have a corrective effect on the immune system in children with acute obstructive bronchitis.

Purpose of the study is to determine the risk factors for the development of $\mathrm{AOB}$ in children of an early age, to give clinical and immunological characteristics and to justify the immunomodulatory therapy of children.

\section{Materials and research methodology}

65 children with AOB, 35 patients with acute simple bronchitis and 20 healthy children were under observation.

\section{Corresponding Author:}

Ibatova Sh. M., Samarkand State Medical Institute, Samarkand, Uzbekistan; Email: barnoshka4675@gmail.com

ISSN: 2231-2196 (Print)

Received: 15.06 .2020
ISSN: 0975-5241 (Online)

Revised: 22.07 .2020
Accepted: 18.08 .2020 
Children with acute obstructive bronchitis were at the age of 6 months up to 3 years old, of whom 39 (60\%) were boys, $26(40 \%)$ were girls. The diagnosis of AO was established according to the classification adopted in 1996 at the Russian Symposium of Pediatricians - Pulmonologists. The diagnosis was based on the identification of the main clinical signs of the disease with the exclusion of diseases occurring with a similar clinical picture.

The immunological study was carried out in the clinical laboratory of the Sam MI clinic. The number of T-lymphocytes (CD3), T-helpers (CD4), T-suppressors (CD8), as well as Blymphocytes (CD19) was determined by a modified method (Yu.F. Garib, 1995). The concentration of serum immunoglobulins A, M, G in peripheral blood was determined by the method of Mancinietal (1965). The phagocytic activity of neutrophils was studied using latex particles (Petrov R.V., 1988).

The immunological examination was carried out taking into account the nature of the therapy: the first group of patients was on traditional treatment with the inclusion of T-activin, and the second group of children was only on traditional treatment.

\section{RESULTS AND DISCUSSION}

The analysis of the examined patients showed that the majority of children have the disease on the age from 3 months to 1 year. In the anamnesis, the presence of respiratory diseases was often noted, which were complicated by acute obstructive bronchitis for 2-3 days. The analysis of the family - hereditary anamnesis showed that $32 \%$ of sick children were born from related marriages, $46.5 \%$ of children had relatives suffering from allergic diseases. The analysis of the initial premorbid background showed that in children with AOB (acute obstructive bronchitis), allergic diathesis was noted in $54.9 \%$, anaemia - in $81.9 \%$, rickets - in $51.0 \%$, part trophy - in $12.5 \%$ and degree I-II hypotrophy - in $48.7 \%$. It was revealed that the average body weight at birth in children with AOB (acute obstructive bronchitis) significantly exceeds (more than $3.5 \mathrm{~kg}$ ) those in children with acute simple bronchitis and the control group.

The carried out immunological studies revealed a decrease in the factors of natural resistance of cellular immunity and the developing transient insufficiency of humoral immunity with an increase in the duration of the disease. The main changes in cellular immunity were expressed in a decrease in the number of T-lymphocytes (CD3) $45.2 \pm 0.8$ compared to $57.3 \pm 0.9 \%$ in children from the control group $(\mathrm{p}<0.01)$. More often, there was an increase in the content of B-lymphocytes (DM19) in patients with AOB (acute obstructive bronchitis) $18.1 \pm 0.3(\mathrm{p}<0.01)$, which is significantly higher than the data with acute bronchitis $16.1 \pm 0.7 \%(\mathrm{p}<0.01)$ and the control group $(\mathrm{p}<0.01)$. There was a tendency towards a decrease in T-suppressors (DM8) in relative and absolute terms in AOB in children (Table 1).

Phagocytic activity of neutrophils in the acute period of the disease was significantly inhibited in the examined patients and amounted to $45.1 \pm 0,(\mathrm{p}<0.01)$. A particularly pronounced decrease in FAN was observed in children with relapses (3-4 times a year) of acute obstructive bronchitis. There was also a significant decrease in the index of phagocytosis and the rate of completed phagocytosis. Changes in the humoral link of immunity were accompanied by a decrease in the concentration of $\operatorname{IgA}(\mathrm{p}<0.01)$ and $\operatorname{IgG}(\mathrm{p}$ $<0.01)$. An increase in the concentration of $\operatorname{IgM}(\mathrm{p}<0.01)$ in children with $\mathrm{AOB}$ indicates that during the height of the disease, the immune response is provided mainly due to antibodies of the IgM class.

Consequently, the humoral link of immunity in the nonclinical manifestations of AOB is characterized mainly by an imbalance in the concentration of immunoglobulins in response to antigenic stimulation. The obtained results of immunological studies served as the basis for the inclusion of immunoprotective drugs in the complex of treatment of AOB in young children and the subsequent dynamic control of the immune response indicators to prevent recurrence of the disease. The indications for their appointment were the presence of clinical signs of immune deficiency, a sluggish inflammatory process, a tendency to the recurrence of AOB, short-term effectiveness of antibiotic therapy.

Table 1: Immunity indices of young children with acute obstructive bronchitis

\begin{tabular}{|c|c|c|c|}
\hline Indicators & $\begin{array}{l}\text { Healthy } \\
\text { children } \\
n=25\end{array}$ & $\begin{array}{c}\text { Children } \\
\text { with simple } \\
\text { bronchitis } \\
\mathbf{n}=35\end{array}$ & $\begin{array}{l}\text { Children with } \\
\text { acute obstruc- } \\
\text { tive bronchi- } \\
\text { tis } n=65\end{array}$ \\
\hline $\begin{array}{l}\text { T-lymphocytes,\% } \\
\text { (SD3) }\end{array}$ & $57 \cdot 3 \pm 0.9$ & $\begin{array}{c}45.2 \pm 0.8 \\
\mathrm{p}<0.01\end{array}$ & $\begin{array}{c}40.1 \pm 0.3 \\
p<0.01\end{array}$ \\
\hline $\begin{array}{l}\text { T-abs. thousand } \\
/ \mu \mathrm{l}\end{array}$ & $1.51 \pm 0.13$ & $\begin{array}{c}1.39 \pm 0.18 \\
\mathrm{p}<0.01\end{array}$ & $\begin{array}{c}1.28 \pm 0.5 \\
\mathrm{p}<0.01\end{array}$ \\
\hline $\begin{array}{l}\text { T-helpers,\% } \\
\text { (CD4) }\end{array}$ & $45.8 \pm 0.8$ & $\begin{array}{c}39.9 \pm 0.2 \\
\mathrm{p}<0.01\end{array}$ & $\begin{array}{c}33.8 \pm 0.6 \\
\mathrm{p}<0.01\end{array}$ \\
\hline $\begin{array}{l}\text { T-suppressors, \% } \\
\text { (CD8) }\end{array}$ & $8.4 \pm 0.3$ & $\begin{array}{c}6.9 \pm 0.29 \\
\mathrm{p}<0.01\end{array}$ & $\begin{array}{l}6.1 \pm 0.1 \\
\mathrm{p}<0.01\end{array}$ \\
\hline $\begin{array}{l}\text { B-lymphocytes,\% } \\
\text { (SD19) }\end{array}$ & $12.3 \pm 0.89$ & $\begin{array}{c}16.1 \pm 0.76 \\
\mathrm{p}<0.01\end{array}$ & $\begin{array}{c}18.1 \pm 0.3 \\
\mathrm{p}<0.01\end{array}$ \\
\hline $\begin{array}{l}\text { Abs. thousand } \\
/ \mu \mathrm{l}\end{array}$ & $0.3 \pm 0.05$ & $\begin{array}{c}0.39 \pm 0.03 \\
\mathrm{p}<0.01\end{array}$ & $\begin{array}{c}0.41 \pm 0.01 \\
\mathrm{p}<0.01\end{array}$ \\
\hline IgA, g/l & $2.18 \pm 0.06$ & $\begin{array}{c}1.65 \pm 0.08 \\
\mathrm{p}<0.01\end{array}$ & $\begin{array}{c}1.53 \pm 0.07 \\
\mathrm{p}<0.01\end{array}$ \\
\hline IgM, g/l & $1.02 \pm 0.1$ & $\begin{array}{c}1.39 \pm 0.3 \\
\mathrm{p}<0.01\end{array}$ & $\begin{array}{c}1.43 \pm 0.7 \\
\mathrm{p}<0.01\end{array}$ \\
\hline $\operatorname{IgG}, \mathrm{g} / \mathrm{l}$ & $9.03 \pm 0.55$ & $\begin{array}{c}7.89 \pm 0.87 \\
\mathrm{p}<0.01\end{array}$ & $\begin{array}{c}7.01 \pm 0.4 \\
\mathrm{p}<0.01\end{array}$ \\
\hline FAN, $\%$ & $59.5 \pm 1.24$ & $\begin{array}{c}47.2 \pm 0.86 \\
\mathrm{p}<0.01\end{array}$ & $\begin{array}{c}45.1 \pm 0.9 \\
\mathrm{p}<0.01\end{array}$ \\
\hline
\end{tabular}


As can be seen from Table 1, the content of T-lymphocytes in patients with simple bronchitis was reduced and amounted to $45.2 \pm 0.8 \%$, compared with the indicators of healthy children $(57.3 \pm 0.9 \%)$, and in children with Acute obstructive bronchitis showed a significant decrease in this indicator $40.1 \pm 0.3 \%$. The content of T-helpers and T-suppressors was also reduced in patients with simple bronchitis - $39.9 \pm 0.2 \%$ and $6.9 \pm 0.29 \%$, and in acute obstructive bronchitis parameters significantly decreased and amounted to $33.8 \pm 0.6 \%$ and $6.1 \pm 0.1 \%$, in the control group the indicators were 45.8 $\pm 0.8 \%$ and $8.4 \pm 0.3 \%$. The content of B-lymphocytes in children with simple bronchitis increased to $16.1 \pm 0,76 \%$, in patients with acute obstructive bronchitis there was a significant increase up to $18.1 \pm 0.3 \%$, in healthy people it was $12.3 \pm 0.89 \%$. The content of immunoglobulins A and $\mathrm{G}$, as can be seen from the table, decreased and amounted to 1.65 $\pm 0.08 \%, 7.89 \pm 0.87 \%$ in children with simple bronchitis, and in acute obstructive bronchitis there was a significant decrease of $1.53 \pm 0,07 \%, 7.01 \pm 0.4 \%$, and in healthy children, the indicators were $2.18 \pm 0.06 \%, 9.03 \pm 0.55$. The level of immunoglobulin $\mathrm{M}$ in patients with simple bronchitis increased and amounted to $1.39 \pm 0.3 \%$, in acute obstructive bronchitis, its significant increase was noted $1.43 \pm 0.7 \%$, in healthy children the indicator was $1.02 \pm 0.1$. Phagocytic activity of neutrophils decreased in patients with acute simple bronchitis and amounted to $47.2 \pm 0.86 \%$, in acute obstructive bronchitis it decreased to $45.1 \pm 0.9 \%$, and in children of the control group, it was $59.5 \pm 1.24 \%$.

The improvement in clinical symptoms and immunological parameters were less pronounced in children with AOB (acute obstructive bronchitis) who were on the traditional method of treatment. Thus, the level of T-lymphocytes ( $p$ $<0.01)$ remained low, the indices of B-lymphocytes $(\mathrm{p}<0.01)$ were high. The content of immunoglobulins did not reach the values of healthy children.

To correct the immunological parameters, patients were prescribed T-activin subcutaneously at the rate of $2 \mu \mathrm{g} / \mathrm{kg}$ of body weight daily for 5 days and the sixth injection one week after injections. Clinically, all children who received T-activin showed positive dynamics. T-activin promotes a significant increase in the relative and absolute number of T-lymphocytes and T-lymphocyte subpopulations (CD4 and CD8). T-activin improves the state of the T-link of the immune system and helps prevent frequent intercurrent diseases, especially with repeated courses of its use. The use of T-activin against the background of traditional therapy has a pronounced positive effect, promotes a more rapid decrease in symptoms of intoxication, as well as relief of various complications of the disease. Comparative analysis of immune response indicators against the background of traditional treatment and with the addition of T-activin revealed a significant increase in B-lymphocytes (CD19) $12.9 \pm 0.76 \%$, an increase in FAN $57.9 \pm 1.34 \%$ and normalization of all immunoglobulins A, M, G.

The studies have shown a significant role of disturbances in individual links of the immune response in the pathogenesis of AR in children, which was the rationale for the use of immunoprotective therapy. An analysis of the results of the inclusion of T-activin in the complex therapy confirmed the effectiveness of treatment, especially in frequently ill children.

\section{CONCLUSION}

1. In young children, risk factors for the development of $\mathrm{AOB}$ are the hereditary burden of allergic diseases, early transfer to artificial and mixed feeding, frequent repeated respiratory infections and inappropriate antibiotic therapy, aggravated premorbid background.

2. Analysis of the links of the cellular link of immunity in young children with AOB showed a significant decrease in the relative and an absolute number of Tlymphocytes and immunoglobulin imbalance in children with AOB.

3. The inclusion of T-activin in the complex therapy of children with AOB increases the effectiveness of treatment, contributes to the normalization of immune status indicators and prevents the development of relapses of the disease.

Acknowledgement: Authors acknowledge the immense help received from the scholars whose articles are cited and included in references of this manuscript. The authors are also grateful to authors / editors / publishers of all those articles, journals and books from where the literature for this article has been reviewed and discussed.

\section{Conflict of interest: None}

\section{REFERENCES}

1. Alferov V.P., Sidorova T.A., Osipyan N.A. Bronchial obstruction in children. Russian family doctor. 2003; 7 (1): 16-22

2. Zaitseva OV Broncho-obstructive syndrome in children. Pediatrics, 2005, No. 4, - PP 94-104.

3. Zakirova U.I. Phenotypic features of Uzbek children with obstructive bronchitis. Uzbekistan medical journal, 2002; 5: 55-58.

4. Ibatova Sh.M. Broncho-obstructive syndrome in young children: prevalence, clinical manifestations, diagnosis and treatment. International scientific journal "Problems of Biology and Medicine”. No. 2017;2 (94): 178-181.

5. Ibatova Sh.M. Retrospective analysis of risk factors for the development of broncho-obstructive syndrome in children. International scientific and practical journal "Health, demography, the ecology of the Finno-Ugric peoples" Ijevsk. 2018; 2: 57-60.

6. Ibatova Sh.M. Some aspects of the broncho-obstructive syndrome in young children Scientific-practical journal "Consilium". Proceedings of the Interregional scientific-practical conference with international participation "Family health - the future of Russia." Ijevsk. \# 1. 2019: 43-45.

7. Ibatova Sh.M., Mamatkulova F.Kh. Broncho-obstructive syndrome in children: prevalence of differential diagnosis and 
prognosis. J. "Problems of Biology and Medicine". Samarkand. 2019; 3:PP 233-236.

8. Rakhimov S.A., Zakirov U.I. Indicators of digital dermatoglyphics of children with obstructive bronchitis of the Uzbek population of a paediatrician, Pediatrics, 2001; 3: 22-26.
9. Shamsiev F.S., Merlyanova E.A., Aminova Kh.U. et al. Influence of risk factors on the clinical course of recurrent bronchitis in children. Paediatrics, 2000;4: 19-22.

10. Yartsev M.N., Yakovleva K.P., Plakhshchenko M.V. Immune deficiency and frequently ill children. Consilium Medical, 2006;1:13-18. 